\title{
語彙テスト項目の分析
}

\section{Analyzing Test Items of Vocabulary}

\section{廣瀬浩二（明倫短期大学）}

\begin{abstract}
Summary
The purpose of this rescarch was to obtain statistical information on lest components. included in English-language dentistry tests administered over a two year period. Two different types of test items were analyzed in order to creat more appropriate test questions. Both types consisted of multiple-choice questions. Type $A$ was composed of one English-language term as a slem and four Japanese-language equivalents as options. A distractor could be selected in the case of an exam sitter not knowing the correct answer. On the other hand, type B included one Japanese term as a stem and four English equivalents as options. All items in both tests were analyzed using classical test theory (CTT) and item response theory (IRT). Results demonstrated a negatively skewed distribution pattern and the curve was sharply peaked (leptokurtic distribution) in type A. In type B, however, the data spread out in a flat curve (platykurtic distribution). It was statistically proved that easy items in type $A$ were more numerous and the number of considerably difficult items increased in type B.
\end{abstract}

\section{1.はじめに}

筆者の勤務する短大歯科衛生士学科の「英語 I」では、1 年生に対し英語歯科 用語を指導する。その教授内容は、主として単語の発音・日本語訳・用語の意 味である。また、課程の評価方法は授業への参加態度・小テスト及び期末テス トから成る。本研究では、小テストに注目した。小テストは原則として授業時 間ごとに実施した。その機能は、前時に学習した用語が確実に理解されている かを確認することである。テストは各回とも約 18 の項目から構成した。平成 9 年度では、英語歯科用語の基幹部分に対し日本語の選択肢を 3 つ配した小テス 卜項目(テストタイプA)を作成した。タイプAのテスト結果を分析したところ、 比較的高い得点圏に受験者が集中し、問題が容易すぎることが判明した。これ は小テストの機能からすれば悪いことではない。だが、受験者にとって多少手 応えのある問題にするためと英語の用語を覚えさせるために、平成 10 年度では 別の小テストを作成した。即ち、日本語歯科用語の基幹部分に対し英語による 4 選択肢を設けたテスト(テストタイプ B)である。いずれのテストタイプも古典的 テスト理論(CTT) と項目応答理論(IRT)の両者によって項目分析を行った。CTT 
による分析では、項目困難度・項目弁別力指数・実質選択肢数の点に注目し、IRT の分析では、1 パラメーター・ロジスティック・モデル(1PLM)を使用し、それ ぞれ項目の項目困難度に注目した。これら 2 タイプのテスト項目を比較分析す ることによって、歯科用語の分野における適切な小テスト作成のための資料を 得ることを本研究の目的とする。

\section{2. 言語テスト技術}

言語テスト技術は Hughes(1989:59-62)によれば、受験者の能力を引き出す手段 であり、次の事項が含まれなければならない。

(1)テスト㥶施者が評価しようとする能力に関して、信頼性・妥当性のある指標 となるような受験者の反応を引き出すこと。

(2)信頼できる得点を引き出すこと。

(3)できる限り時間と労力を節約すること。

(4)有益な波及効果(backwash effect)があること。

これに関連して本研究で作成した小テストで、(1)授業で指導した英語歯科用 語の習得の度合を評価できる。(2)テストタイプ A では、信頼性係数(アルファ係 数)が 0.825 と高い数值を得ている(タイプ B では 0.695)。(3) 多肢選択式テスト (Multiple choice)であるため、採点が比較的容易である。(4)基幹部分を英語から 日本語に、選択肢を日本語から英語に変更したことによって、授業においても 日本語訳より英語の用語に注目するようになるであろう。

\section{3. 多肢選択式テスト}

多肢選択式テストには、一つの「正答」と複数の錯乱肢(distractors)が必要で ある。だが、時には実際の項目の中には正答が複数ある場合、正答がない場合、 効果的でない錯乱肢が配列してある場合などが見受けられる(Frary, 1995)。良い テスト項目を作成することは困難なことである。テスト項目を作成する際に最 も重要なことは、「正答」はまぎれもない正答でなければならない(Alderson et al., 1995)ことである。この指摘は、このタイプのテストにこれまで果たして正答か どうか判断できない項目が見受けられたことを示している。この点に関して本 研究では、作成した各テスト項目には「正答」が一つしか存在しないことを確 認した上でテストを実施した。

ESP(English for Specific Purposes)の分野における英語の役割(Richards et al., 1992)、特に歯科衛生士のためのコースにおける役割を考えた場合、用語指導と 診療所における英会話指導が主要な指導事項となる。本研究では、用語指導に 焦点化し、そこで使用した小テストを分析対象とした。多肢選択式テストには、 認識(recognition)の知識を評価できるが、産出(production)の知識までは評価でき ない、といった特徵がある。歯科衛生士は歯科医師の指導のもとでカルテ作成 
を行うため、それらの用語は正確に綴りを産出できる段階までは要求せず、認 識の段階に留めておいて良いと判断した。

\section{4. 対象および方法}

\section{1 対象}

本研究の対象者は、筆者の勤務する短大歯科衛生士学科 1 年生平成 9 年度 75 名、10 年度 78 名である。テストは平成 9 年 12 月(テストタイプ A)及び平成 10 年 12 月(テストタイプB)に通常の授業時間内に実施した。

\section{2 方法}

\subsection{1 テスト項目の作成}

各年度とも 11 月までに指導した 165 の英語歯科用語についておよそ 18 項目 から成る小テストを 9 回分作成した。本研究では、その中から 1 回分を任意に 選択し比較検討した。

平成 9 年度ではテストタイプ $\mathrm{A}$ を作成したが、テスト問題が容易すぎたため、 学習者の取り組みに積極さが欠けていた。そこで、平成 10 年度ではテスト問題 の難易度を上げて、授業への積極的参加・英語用語に対する意識の向上など良 い波及効果を期待してテストタイプ B を作成した。変更点は次の通りである。 (1)両タイプとも多肢選択式テストであるが、基幹部分(stem)は夕イプ A では英語、 タイプ B では日本語の歯科用語であった。(2)選択肢は夕イプ A では日本語、夕 イプ B では英語であった。(3)タイプ A では“?”で表示した錯乱肢を設けたが、 タイプ B ではその錯乱肢を除去し選択肢の数を 3 から 4 に増した。

テストタイプ A は、表 1 に示すように、最初に英語の用語を挙げ、次に該当 する日本語の選択肢 3 つと“? (全くわからない場合に選択する)を配列した。受 験者には、各項目において英語に相当する日本語の用語を $\mathrm{a} \sim \mathrm{d}$ の中から選び、 解答欄に記入させた。尚、a〜c のいずれが正解であるかわからない場合には、 d.?を選択するよう指示した。

テストタイプ B は、表 2 に示すように、最初に日本語の用語を挙げ、次に日 本語に対応する英語による選択肢 4 つ(正しい選択肢 1、錯乱肢 3)を配列した。 受験者には、各項目において日本語に対応する英語の用語をア〜エの中から選 び、解答欄に記入させた。

表1.テストタイプA
(1)carving knife ( )a.切断刀, b.彫刻刀, c.両刃刀, d.?

(2)mallet ( )a.触診, b.悪性腫瘍, c.槌, d.?

(3)central incisor ( )a.中切歯, b.側切歯, c. 乳切歯, d.?

(4)lateral incisor ( )a.側切歯, b. 乳切歯, c.中切歯, d.?

(5)recall ( )a.顮関節検查, b. 定期検查, c. 知覚検査, d.?

(6)block anaesthesia ( )a.伝達麻酔, b.表面麻酔 c.浸潤麻酔, d.? 
(7)objective symptom ( a.自覚症状, b.間接症状, c.他覚症状, d.?

(8)inverted cone bur ( a.倒立円錐バー, b.仕上げバー, c.円形バー, d.?

(9)silver impregnation method（）a.内観法, b.銀含浸, c.鍍銀法, d.?

(10)dry socket （）a.ロ腔乾燥, b.ドライソケット, c.歯周ポケット, d.?

(11)floss silk（）a.塗蝋絹糸, b.外科用絹糸, c.処女絹系, d.?

(12)milk teeth( ） a.誕生歯, b.新生巟歯, c.乳歯, d.?

（13)cyst（） a.囊胞, b.歯根囊胞, c.歯肉裹胞, d.?

(14)incision of abscess（） a.歯槽膿瘍, b.口蓋膿瘍, c.膿瘍切開, d.?

(15)saliva ejector（） a.安静時唾液, b.排唾器, c.神経節唾液, d.?

(16)dressing forceps( ) a.麦粒鉗子, b.抜歯鉗子, c.骨鉗子, d.?

(17)extraction of the tooth( ) a.脱落歯, b.人工歯, c.抜歯, d.?

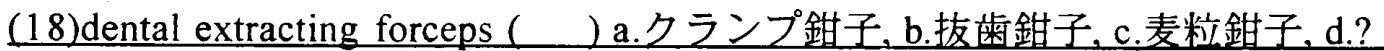

表2.テストタイプB

(1)彫刻刀（）ア、carvone knife イ、carvacrol knife ウ、carven knife 工、 carving knife

(2)桘（）ア、mallet イ、mallee ウ、malleolus エ、malleus

(3)中切歯 ( ) ア、 centric incisor イ、centroclinal incisor ウ、 centripetal incisor

I. central incisor

(4)側切歯 ( )ア、latent incisor イ、lateral incisor ウ、 later incisor エ、latter incisor

(5)定期検査（）ア、recap イ、 recall ウ、recast 工、recce

(6)伝達麻酔（）ア、block anaesthesiologyイ、block anaesthetic ウ、block anaesthesia

工, block anesthetics

（7)他覚症状（） ア、objective symptom イ、objective symptomatology

ウ、 objective symptomology I、 objective symphysis

(8)倒立円錐バー（）ア、inverted comma bur イ、inverted con bur ウ、inverted cone bar I, inverted cone bur

(9)鍍銀法（ ）ア、silver impregnant method イ、 silver imprescriptibility method

ウ、 silver impregnation method $工$ 、 silver imprecation method

(10)ドライソケット（）ア、dry sock イ、dory socket ウ、dry socket エ、dry sock

(11)塗蝋絹糸（）ア、floss silk イ、flossy silk ウ、florin silk 工、florist silk

(12)乳菌( ）ア、mill teeth イ、milk teeth ウ、milky teeth エ、millcake teeth

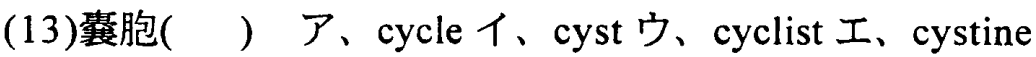

(14)膿瘍切開（） ア、 incision of abscess イ、 incisor of abscess ウ、incisor of absence 工、 incision of absence

(15)排唾器（）ア、salivary ejector イ、salivary ejection ウ、saliva ejection エ、saliva ejector 
(16)麦粒鉗子（）ア、dressed forceps イ、dressing forceps ウ、dressing forcite I. dressed forcite

(17)抜歯( ) ア、extraction of the tooth イ、 extractor of the tooth

ウ、 extradition of the tooth I、 extraneousness of the tooth

(18) 抜歯鉗子( ) ア、dental extortionary forceps 个、, dental extortionary forcite $\eta$, dental extracting forceps $I$, dental extracting forcite

\subsection{2 分析方法}

テスト結果のデータ分析に際し、大友(1996)付属のテスト・データ分析プログ ラム TDAP(Test Data Analysis Program) Ver.1.0 (Copyright: Kenji Ohtomo \& Youichi Nakamura, 1996)を使用した。

\section{5. 結果と考察}

\section{1 基礎統計量}

表 3. 基礎統計量一覧表

\begin{tabular}{lcc}
\hline \hline & タイプA & タイプ B \\
\hline 得点の総計 & 1235 & 1219 \\
最小得点 & 3 & 8 \\
最大得点 & 18 & 18 \\
Median & 17 & 16 \\
Range & 15 & 10 \\
平均 & 16.467 & 15.628 \\
分散 & 5.876 & 5.618 \\
標準偏差 & 2.424 & 2.370 \\
Skewness & -2.934 & -1.229 \\
Kurtosis & 11.438 & 1.147 \\
\hline
\end{tabular}

表 3 は、テストタイプ A と B の基礎統計量をまとめたものである。それによ ると、 B では A より得点の総計は隇少し(1235 $\rightarrow 1219)$ 、最低得点は高くなった $(3$ $\rightarrow 8)$ 、最高得点は変わらない(18)。平均が低くなった $(16.467 \rightarrow 15.628)$ た、 Median も低くなった $(17 \rightarrow 16)$ 。しかし、平均值が依然として高い位置にあるた

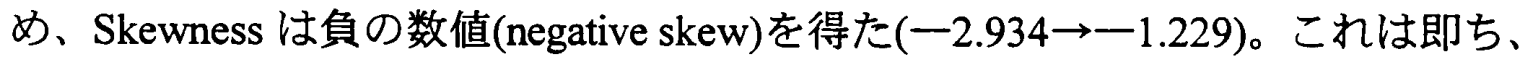
比較的高い得点の位置に受験者が多く集中したことを示している。ただ、タイ プ B ではその程度が A より緩やかであった。どちらかといえば問題が比較的容 易であったとの解釈もできるが、一方、よく学習して目標の達成に近づいた学 習者が多かった、とも解釈できる。そもそも、本研究で実施した小テストは形 成的評価(formative evaluation)の一つとして位置付けられ、目標基準準拠テスト 
(criterion-referenced test)であった。この小テストの機能を考えると、これは必ず しも問題とはならず、むしろ望ましいものとも考えられる。ただ、ある程度難 しい問題も配置して学習者の学習意欲も喚起したいところである。最高得点と

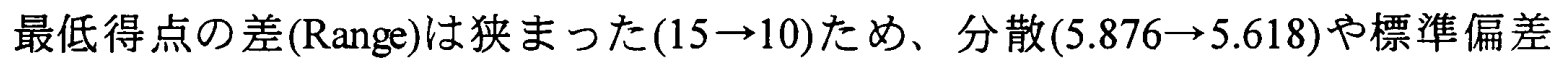
$(2.424 \rightarrow 2.370)$ 数值も小さくなった。Kurtosis の数值はかなり小さくなった $(11.438 \rightarrow 1.147) 。$ テストタイプ A では得点の集中がみられたが、タイプ B では 得点の分布曲線は平坦なカーブを描き、得点分布の集中が回避される結果とな つた。

\subsection{CTT による項目分析}

表 4 は、CTT によって分析した項目困難度指数・項目弁別力指数・実質選択 肢数をテストタイプ A, B についてまとめたものである。

表 4.CTTによる項目分析結果

NO. \begin{tabular}{llll}
\multicolumn{2}{c}{ DIFF } & & \multicolumn{2}{c}{ DISC } & & AENO \\
$\mathrm{A}$ & $\mathrm{B}$ & $\mathrm{B}$ & $\mathrm{A}$
\end{tabular}

\begin{tabular}{lllllll}
\hline 1 & 0.920 & 0.962 & 0.077 & 0.083 & 1.433 & 1.206 \\
2 & 0.973 & 0.974 & 0.646 & 0.286 & 1.152 & 1.127 \\
3 & 0.947 & 0.962 & 0.535 & 0.367 & 1.278 & 1.206 \\
4 & 0.947 & 0.897 & 0.731 & 0.398 & 1.302 & 1.527 \\
5 & 0.987 & 0.987 & 0.646 & 0.031 & 1.073 & 1.071 \\
6 & 0.920 & 0.808 & 0.422 & 0.466 & 1.397 & 1.925 \\
7 & 0.787 & 0.885 & 0.637 & 0.560 & 1.861 & 1.604 \\
8 & 0.893 & 0.769 & 0.548 & 0.214 & 1.569 & 1.904 \\
9 & 0.920 & 0.692 & 0.381 & 0.561 & 1.397 & 2.568 \\
10 & 0.947 & 0.821 & 0.535 & 0.071 & 1.278 & 1.601 \\
11 & 0.920 & 0.910 & 0.543 & 0.468 & 1.433 & 1.474 \\
12 & 0.987 & 0.974 & 0.646 & 0.182 & 1.073 & 1.127 \\
13 & 0.920 & 0.846 & 0.564 & 0.737 & 1.322 & 1.769 \\
14 & 0.667 & 0.718 & 0.580 & 0.499 & 2.589 & 2.375 \\
15 & 0.960 & 0.821 & 0.545 & 0.284 & 1.213 & 1.801 \\
16 & 0.907 & 0.897 & 0.553 & 0.542 & 1.508 & 1.527 \\
17 & 0.880 & 0.833 & 0.596 & 0.606 & 1.626 & 1.569 \\
18 & 0.960 & 0.885 & 0.573 & 0.628 & 1.236 & 1.598 \\
\hline
\end{tabular}

$<$ NOTES>

DIFF $=$ 項目困難度指数(Item difficulty index) 
DISC $=$ 項目弁別力指数 $($ Discrimination power index $)$

AENO =実質選択肢数(Actual equivalent number of options)

CTT による項目分析では、特に、項目困難度、項目弁別力指数及び実質選択 肢数に注目した。項目困難度は 0.500 が最も適切である(Henning, 1987:49-50)、と いわれる。本研究で作成した 18 項目の中では、項目 14(タイプ A) と項目 9(タイ プ B)が最も適切なテスト項目に近いといえる。表 5 は、項目困難度の度数を小 数点第 1 位まででまとめたものである。

表 5.項且困難度度数別項目数

\begin{tabular}{lcc} 
& タイプA & タイプB \\
\hline 0.9 & 14 & 6 \\
0.8 & 2 & 9 \\
0.7 & 1 & 2 \\
0.6 & 1 & 1 \\
\hline
\end{tabular}

表 5 によると、度数が 0.9 ポイント代では、タイプ A で 14 項目、B で 6 項目だ が、0.8 ポイント代では、逆に、タイプ A が 2 項目、B が 9 項目となっている。 タイプ B の方が、A より極端に易しい項目が少なくなっている。この点では、 タイプ B を作成した意図が実現された。だが、いずれのタイプも易しい項目や かなり易しい項目が多いため、これらの項目の配列の仕方を考慮するなど工夫 する必要がある。

また、項目弁別力指数(discrimination index)に関しては、一説には+ 0.4 若くは それ以上が満足する数值といわれるが、特に決まった数値はない。ただ、負の 数値を示した場合には、明らかに不良項目で除外若くは改訂の必要がある (Alderson et al., 1995:82)が、該当する項目はなかった。

表 6 は、実質選択肢数をポイント別に配列し直したものである。タイプ B で は、A よりも実質選択肢数のポイントの高い項目が多く確認できる。タイプ A では“?”の選択肢を設定していたが、実際に“?”を選択した受験者はほとんど いなかった。そのため、実質的には 3 選択肢であったと考えてよい。その点で は、タイプBの方が赛質選択肢数が多くなって当然といえる。 表 6. 赛質選択肢数

\begin{tabular}{lcc} 
& タイプA & タイプB \\
\hline 1.0 & 2 & 1 \\
1.1 & 1 & 2 \\
1.2 & 4 & 2 \\
1.3 & 4 & \\
1.4 & 2 & 1 \\
1.5 & 2 & 4
\end{tabular}




\begin{tabular}{lll}
1.6 & 1 & 2 \\
1.7 & & 1 \\
1.8 & 1 & 1 \\
1.9 & & 2 \\
2.0 & & \\
2.3 & & 1 \\
2.5 & 1 & 1 \\
\hline
\end{tabular}

\subsection{IRT による項目分析}

本研究では、IRT の1 パラメーター・ロジスティック・モデル(1PLM)により、 タイプ A と B の双方を分析した。1PLM はその困難度によってのみ各テスト項 目を記述する(Lozier and Chalhoub-Deville, 1997:4)という特徵を持つことから、本 研究でも各テストタイプの最終項目困難度を比較した。表 7 は、項目困難度パ ラメーターをタイプ A とタイプ B でまとめたものである。

表 7. IRT による項目困難度

\begin{tabular}{|c|c|c|}
\hline No. & タイプA & タイプ B \\
\hline 1 & 0.288 & -0.919 \\
\hline 2 & -1.206 & -1.765 \\
\hline 3 & -0.283 & -0.919 \\
\hline 4 & -0.283 & -0.025 \\
\hline 5 & -2.096 & -2.589 \\
\hline 6 & 0.288 & 0.882 \\
\hline 7 & 1.919 & 0.135 \\
\hline 8 & 0.717 & 1.179 \\
\hline 9 & 0.288 & 1.706 \\
\hline 10 & -1.206 & 0.775 \\
\hline 11 & 0.288 & -0.203 \\
\hline 12 & -2.096 & -1.765 \\
\hline 13 & 0.288 & 0.543 \\
\hline 14 & 3.024 & 1.537 \\
\hline 15 & -0.672 & 0.775 \\
\hline 16 & 0.515 & -0.025 \\
\hline 17 & 0.901 & 0.543 \\
\hline 18 & -0.672 & 0.135 \\
\hline
\end{tabular}


既に 3.2.1 で述べたように、テストタイプ B ではタイプ A より若干難易度が 増すのではないかとの予想のもとに、項目内容を変更した。即ち、各項目とも 基幹部分(stem)を英語から日本語に、選択肢を日本語から英語に変更し、選択肢 の数を増した。この変更には学習者の注意を日本語より英語用語に向けさせる、 という意図もあった。テストの結果、タイプ B でも平均值は依然として高い位 置にはあるが若干の低下をみた。総得点が減少し、得点の集中的な分布が解消 した。

さて、項目困難度を表す数值には絶対的な意味はなく、その数值は平均值と 比較して難しいか容易かを示しているに過ぎない(Woods \& Baker, 1985:128)。即 ち、項目困難度は平均が 0 で、正の数值が大きくなるに従って困難さを増し、 負の数値が大きくなるに従って容易になる(Woods \& Baker, 1985:126-127)ことを 意味する。この観点にそって表 7 を検討すると、タイプ A の中では、項目番号 5 と 12 は負の最大数値を持つことから最も容易であると考えられるし、項目番 号 14 は正の最大数值を持つことから最も難しい項目であると判断できる。また、 タイプ $\mathrm{B}$ の中では、項目番号 5 は負の最大数值で最も容易、項目番号 9 が正の 最大数値で最も難しい項目と考えられる。

さらに、Wright and Stone(1979:46-54)の例示によると、タイプ A では、nos.5, 12 はかなり易しい項目、nos.1, 2, 3, 4, 6, 9, 10, 11, 13, 15, 18 はやや難しい項目、nos.7, 8,16,17 はかなり難しい項目、no.14 は非常に難しい項目と言える。タイプ B で は、no.5 はかなり易しい項目、nos.1, 2, 3, 4, 7, 11, 12, 16, 18 はやや難しい項目、 nos.6, 8, 9,10,13,14,15, 17 はかなり難しい項目と考えられる。タイプ B は A と 比較して、かなり易しい項目が減少し $(2 \rightarrow 1)$ 、やや難しい項目も減少し $(11 \rightarrow 9)$ 、 逆に、かなり難しい項目が増加した $(4 \rightarrow 8)$ 。このことから、タイプ B は A より テスト項目の困難度は高くなり、タイプ B を作成した目的が達成できた。

テスト結果の分析に使用した One-Parameter (Rasch) Model (1PLM)で必要な受 験者は 100 名(Alderson et al, 1995:91)と言われる。例えば、ミネソタ大学で実施 された入学時と卒業時の学生の言語能力(フランス語・ドイツ語・スペイン語) の測定の際には、充分な学生数が確保され Two-Parameter Model (2PLM)の使用 が可能であった(Lozier and Chalhoub-Deville, 1997:5)。本研究においては、1PLM を使用するには受験者数はやや不足していた。実際の教育現場でテスト項目の 分析を行い次年度でも使用できるようにすることは重要である。ただ、教育現 場では必ずしも受験者数に関する要件を満たせるとは限らない。

\section{6. 結論}

本研究の目的は、2 年間に渡って作成した小テスト、タイプ A と B の項目分 析を行い適切な小テストを作成するための資料を得ることであった。テスト結 
果を CTT とIRT によって分析した。分析の結果、タイプ A では容易な項目が 多く、学習者はあまり準備をしなくとも問題に正解できた。また、基幹部分が 英語、選択肢が日本語であったため、学習者は英語よりも日本語訳に注目する 傾向が観察できた。一方、新たにテストタイプ B の項目を作成し直したことに よって、困難度の高い項目数が増え、極端な得点分布の偏りが改善された。

今後の課題は、英語歯科用語に関するテスト項目をさらに増やすこと、可能 な限り適切な受験者数を確保することである。項目銀行(item banks)を発展させ 活用することは、膨大な時間と専門的知識が必要である(Hughes, 1989:61)が、テ スト問題の有効活用のため、さらにデー夕を蓄積を目指すものである。

\section{参考文献}

Alderson, J. C., Clapham, C. \& Wall, A. D. 1995. Language Test Construction and Evaluation. Cambridge: Cambridge University Press.

Frary, R. B. 1995. More Multiple-Choice Item Writing Do's and Don'ts. ERIC Digest. Washington, DC: ERIC Clearinghouse on Assessment and Evaluation.

Henning, G. 1987. A Guide to Language Testing. Boston, MA: Heinle \& Heinle Publishers.

Hughes, A. 1989. Testing for Language Teachers. Cambridge: Cambridge University Press.

Lozier, V. M. \& Chalhoub-Deville, M. 1997. Preliminary Item Response Theory Analysis of the University of Minnesota CLA Language Proficiency Tests in French, German, and Spanish. Minneapolis: Center for Advanced Research on Language Acquisition, University of Minnesota.

Richards, J. C., Platt, J. \& Platt, H. 1992. Longman Dictionary of Language Teaching and Applied Linguistics. Harlow: Longman.

Woods, A. \& Baker, R. 1985. Item Response Theory. Language Testing, 2, 117-140.

Wright, B. D. \& Stone, M. H. 1979. Best Test Design. Chicago: MESA Press.

大友賢二 1996. 『項目応答理論入門』東京 : 大修館書店 